\title{
Demystifying the Effect of Narrow Reading on EFL Learners' Vocabulary Recall and Retention
}

\author{
Marziyeh Abdollahi' ${ }^{1,2}$ and Mohammad Taghi Farvardin ${ }^{2}$ \\ ${ }^{1}$ Department of ELT, Khouzestan Science and Research Branch, Islamic Azad University, Ahvaz, Iran \\ ${ }^{2}$ Department of ELT, Ahvaz Branch, Islamic Azad University, Ahvaz, Iran \\ Correspondence should be addressed to Mohammad Taghi Farvardin; farvardin@iauahvaz.ac.ir
}

Received 29 April 2016; Revised 21 July 2016; Accepted 18 September 2016

Academic Editor: Jan Elen

Copyright ( 2016 M. Abdollahi and M. T. Farvardin. This is an open access article distributed under the Creative Commons Attribution License, which permits unrestricted use, distribution, and reproduction in any medium, provided the original work is properly cited.

\begin{abstract}
The aim of the present study was to explore the effect of narrow reading on English as foreign language (EFL) learners' vocabulary recall and retention. To this end, 60 senior high school students studying at Tarbiyat High School in Mahshahr, Iran, were selected from four intact classes. The participants were then divided into two equal groups, experimental and control. Ten words which were unknown to the participants were selected as target words. The experimental group received thematically related passages while the control group was given reading passages of different topics. The immediate posttest was given to the participants two days after the treatment. Afterwards, two delayed posttests were administered with two week intervals. The scores were analyzed through two-way repeated measures ANOVA, Bonferroni pairwise comparisons, and independent samples $t$-tests. The results revealed that the experimental group outperformed the control group in all posttests. The implications arising from the findings and suggestions for future research were explained.
\end{abstract}

\section{Introduction}

Vocabulary is a fundamental part of language learning and a significant means of communication [1]. Since understanding any language requires the knowledge of its vocabulary, learning vocabulary is a very important part of a language. What is generally accepted is that vocabulary is acquired incidentally as a by-product of other cognitive exercises, such as reading, which involve comprehension [2]. In fact, readers do not know that they acquire vocabulary while they read, but they subconsciously absorb meaning [3]. Kintsch [4] argued that reader's comprehension of text can be facilitated by the retrieval of information associated with a stored schema in long-term memory. This process of linking the words and text with the reader's stored background knowledge can be affected by the strength of connections between the more global or higher-level concepts and the words on the page at the more local level [4].

In the same vein, narrow reading (NR) was proposed as an effective technique in enhancing second language (L2)/foreign language learners' vocabulary knowledge [5].
NR is referred to as "reading in only one genre, one subject matter, or the work of one author" [6, page 58]. Krashen [7] proposed that NR is an effective method to grow vocabulary because it guides L2 learners in coming across the topicrelated words recurrently in diverse contexts. By persistently reading on a certain topic, learners can develop a wide array of knowledge on the topic as well as the vocabulary involved [6]. As an advocate of input-based language learning, Krashen [5] proposed that NR in any single topic area provides rich exposure to related vocabulary and contexts.

1.1. Literature Review. English has been a leading language for global communication in the 21st century, and hence communicative competence has become an essential skill [8]. Communicative competence is the ability to use language properly in the process of interaction with the social environment [9]. Some scholars [10, 11] have also supported Hymes' idea that communicative competence is the ability to use language correctly and express suitable behavior in cultural context of communication. Schmitt [12] argued that vocabulary knowledge "is central to communicative competence and to the 
acquisition of a second language" (page 55). Vocabulary knowledge is often viewed as an indispensable tool for L2 learners because a limited vocabulary in an L2 hinders successful communication. In English as a second language (ESL) and English as a foreign language (EFL), learning vocabulary items plays a key role in all language skills (i.e., listening, speaking, reading, and writing) [13]. Moreover, as Rivers [14] argued adequate vocabulary knowledge is crucial for successful use of an L2 because without an extensive vocabulary, we will not be able to use the structures and functions we may have learned for comprehensible communication.

"The area of vocabulary learning is divided into two major categories, incidental and intentional vocabulary learning" [15, page 2]. Researchers have made a distinction between incidental and intentional vocabulary learning. Incidental vocabulary is defined as the "learning of vocabulary as the by-product of any activity not explicitly geared to vocabulary learning" [16, page 2]. On the other hand, intentional vocabulary learning is referred to as "any activity geared at committing lexical information to memory" [17, page 271]. Except for the first few thousand most common words, L2 vocabulary is largely acquired incidentally [18]. Moreover, it is emphasized that incidental vocabulary learning has a vital role in vocabulary learning and is preferred to intentional learning because it is individualized, it occurs in a contextualized form giving learners a sense of using words in real situations, and it enables vocabulary acquisition and reading to occur simultaneously [18].

Hatch and Brown [19] indicated two kinds of vocabulary knowledge, namely, receptive and productive. Receptive vocabulary knowledge refers to the ability to understand a word when it is heard or seen [1], whereas productive vocabulary knowledge means to be able to use a word correctly in a written work or a speech [20].

Krashen [5] believed that vocabulary learning occurs through comprehensible input. He also maintained that competence in vocabulary is most efficiently attained by comprehensible input in the form of reading that contains structure a little beyond our current level of linguistic competence " $i+1$ " [21]. At this level, the learner is able to use the textual context to fill in the gaps in understanding. In fact, one of the most commonly accepted views of vocabulary acquisition is that L2 vocabulary learning occurs incidentally through comprehensible input while reading a text [7].

Using different vocabulary learning strategies may lead to a very different kind of learning [5]. Learning vocabulary from the context and incidental learning as opposed to direct intentional learning are two different ways of learning vocabulary [22]. Paribakht and Wesche [23] declared that incidental vocabulary learning takes place when "learners are focused on comprehending meaning rather than on the explicit goal of learning new words" (p. 176). That is to say, salient attention is directed to some other factors other than acquisition of vocabulary while learners are engaged in reading.

Reading on one specific subject means that much of the topic-focused vocabulary will be repeated across texts. It facilitates the reading process and affords the reader a better chance of comprehending and learning vocabulary. Krashen [7] described various ways through which L2 learners can gain multiple exposures to new language structures and words in a comprehensible context through NR. NR is reading texts by one author or about a single topic of interest, which helps ensure comprehension and natural repetition of vocabulary and grammar [7]. According to Krashen [7], reading a series of thematically linked texts can help learners understand meanings of words and become aware of the appropriate use of words. In other words, when learners read supplementary texts that are thematically linked, their productive and receptive vocabulary knowledge will be enhanced [7]. Several studies on EFL learning have demonstrated that NR can help learners enrich their vocabulary knowledge $[6,24,25]$. The findings of these studies imply that NR can be an important source for vocabulary acquisition.

In order to address the long-term effect of reading on vocabulary retention, Waring and Takaki [26] investigated the rate at which vocabulary was learned from reading a graded reader in a classroom-based study. Fifteen female Japanese EFL learners were asked to recall 25 substitute words (i.e., plausible English words for real English words like yoot for yes) at three different times: immediately after reading, one week later, and three months later. Waring and Takaki [26] found the possibility of incidental vocabulary learning through reading and showed higher acquisition and retention rates among words of frequent occurrence. The authors suggested that there was a 50-percent chance of correctly identifying word form in 3 months later if learners met the word eight times or more.

Cho et al. [6] did a study to explore EFL learners' vocabulary gains through NR. In this study, Cho et al. [6] asked 37 learners enrolled in an elementary school in Korea to read the Clifford book series (short fiction stories written for Englishspeaking children), in a class that lasted 40 minutes per week over a period of three months. The participants were tested on 12 vocabulary items selected from both the book series and their English textbook at the first and last week of the study. A questionnaire inquiring about their interest in reading was also distributed before and after the treatment. It was found that their level of interest and confidence in reading improved drastically at the end of the study. The results also revealed that the participants made significant vocabulary gains after NR.

Min [27] conducted a quasi-experimental study to compare the effect of reading plus vocabulary enhancement activities (RV) and NR on vocabulary acquisition and retention among EFL secondary school students. In a study of expository NR, Chinese-speaking Taiwanese high school students who read topically related informational texts made statistically significant gains in receptive and expressive vocabulary during a five-week period and retained significant vocabulary knowledge three months later. The results showed that the RV group demonstrated significantly more knowledge about the target vocabulary than the NR group on the acquisition and retention tests. The researcher concluded that reading and focused vocabulary exercises are more effective and efficient than the NR in enhancing target vocabulary acquisition and retention among EFL secondary students. 
In a recent study, Kang [28] investigated the impact of NR on L2 learners' lexical growth. To this end, a total number of 61 high intermediate learners read a series of texts either thematically related (narrow) or unrelated (wide) over one month. The findings showed that NR considerably facilitated L2 learners' understanding of meanings of target words and the ability to use them appropriately.

1.2. Statement of the Problem and Purpose. EFL teachers are caught in a dilemma that which approach can be effective for teaching and learning vocabulary. NR has been proposed as an influential technique in enhancing L2 learners' vocabulary learning. However, there remains a relative dearth of empirical studies that test the effect of NR on L2 learners' vocabulary learning. Moreover, the majority of the previous studies either worked on vocabulary recall alone or studied the effect of NR on vocabulary retention. They even lacked delayed posttests to measure the learners' retention. Therefore, to fill in the existing gap, this study aimed to investigate whether NR has positive effect on L2 learners' vocabulary recall and retention. In addition, the present study examined multiple aspects of vocabulary knowledge by including both receptive and productive vocabulary measures.

1.3. Research Questions. Krashen's [21] input hypothesis proposed that language is acquired when learners are exposed to a large amount of comprehensible input, which is beyond their present level of language knowledge. Comprehensible input is easy to provide through NR because common vocabulary and discourse are often repeated within single topics or similar contexts. NR also makes multiple exposures to the same language features possible in instructional settings [21]. In order to delve more into the effects of NR, which is based on Krashen's comprehensible input hypothesis [21], on the recall and retention of EFL learners' receptive and productive vocabulary knowledge, the following research questions have been addressed:

Q1: Will narrow reading improve the recall of EFL learners' receptive vocabulary knowledge?

Q2: Will narrow reading improve the recall of EFL learners' productive vocabulary knowledge?

Q3: Will narrow reading improve the retention of EFL learners' receptive vocabulary knowledge?

Q4: Will narrow reading improve the retention of EFL learners' productive vocabulary knowledge?

1.4. Research Hypotheses. Based on the previous studies on NR, Krashen's [21] input hypothesis, Krashen's [7] claim on the positive effects of NR on both receptive and productive vocabulary knowledge, and the research questions, these hypotheses were formulated:

H1: Narrow reading will improve the recall of EFL learners' receptive vocabulary knowledge.

$\mathrm{H} 2$ : Narrow reading will improve the recall of EFL learners' productive vocabulary knowledge.
$\mathrm{H} 3$ : Narrow reading will improve the retention of EFL learners' receptive vocabulary knowledge.

H4: Narrow reading will improve the retention of EFL learners' productive vocabulary knowledge.

\section{Methods}

This study adopted an experimental design involving pretest, treatment, and three posttests. The participants received treatment in four sessions during four weeks, beginning one week after the pretest. The delayed posttests were administered after the last treatment session with a two-week interval.

2.1. Participants and Setting. Sixty female senior high school students at Tarbiyat High School in Mahshahr, Iran, were selected. The participants' age ranged between 17 to 19 years $(\mathrm{M}=17.70, \mathrm{SD}=0.32)$. The majority of the participants came from middle-class families as indicated by a self-report questionnaire on demographic information and also by considering their parents' education level and family income. The annual net income after tax of the participants' family, as obtained from the questionnaire, ranged from $\$ 7000$ to $\$ 9000$ which is considered a middle-ranged income in Iran. The participants' parents had spent 14 to 18 years in the educational system of Iran. In other words, they had Associate's (31\%), Bachelor's (43\%), or Master's (26\%) degree. Moreover, most of the participants had only been studying English in school setting for about five years. The participants' English proficiency was also assessed through Oxford Placement Test (OPT) [29] that includes two sections, grammar and listening, each of which consists of 100 items. Each correct item received 1 point. Therefore, the maximum possible score was 200. It was found that the participants were at lowerintermediate level of English proficiency $(\mathrm{M}=126.32, \mathrm{SD}=$ 2.86). The band score for lower-intermediate level is 120 to 134. The participants in four intact classes were randomly divided into two equal groups, experimental and control $(n=$ 30 each). The family income, parents' educational level, and OPT scores of the participants were controlled across the two groups. In this study, the experimental group were required to read passages about a related topic, and the control group read passages with unrelated topics.

\subsection{Instruments and Materials}

2.2.1. Target Words. The target words were selected from the 504 Absolutely Essential Words [30] (Appendix A). To ensure the unfamiliarity of the target words to the participants, their teachers confirmed that the words could be unknown to the participants. Moreover, the target words appeared in the pretest one week before the treatment. The pretest included 20 English words and 10 target words for the study along with 10 distractors. All the participants were asked to supply the L1 (Persian) meaning of the target words in the pretest and it was found that none of the participants could provide the L1 meaning of the target words. 
TABLE 1: Readability and word count of the passages.

\begin{tabular}{|c|c|c|c|c|c|c|c|}
\hline \multirow[b]{2}{*}{ Topic } & \multirow{2}{*}{$\begin{array}{l}\text { Main passage (both groups) } \\
\text { Cellphones: hang up or keep } \\
\text { talking }\end{array}$} & \multicolumn{3}{|c|}{ Experimental group } & \multicolumn{3}{|c|}{ Control group } \\
\hline & & $\begin{array}{l}\text { Cellphone } \\
\text { risks }\end{array}$ & $\begin{array}{c}\text { Cellphone as new } \\
\text { invention }\end{array}$ & $\begin{array}{c}\text { Cellphone at } \\
\text { school }\end{array}$ & Money & Smoking & $\begin{array}{c}\text { Global } \\
\text { warming }\end{array}$ \\
\hline Word count & 428 & 412 & 426 & 414 & 452 & 411 & 462 \\
\hline Readability & 7.5 & 9.7 & 8 & 9.5 & 9.1 & 9.3 & 9.4 \\
\hline
\end{tabular}

2.2.2. Pilot Test. A pilot study was conducted with one class (30 students) in another school before the main phase of the study to investigate the reliability of the reading tests and to examine how much time it would take the participants to complete the tasks. These participants did not take part in the main study. During piloting the passages, the researchers detected that the target words were above the students' level since the students had no prior knowledge of them. Some of the students tried to look up the meaning of the target words in dictionary or ask about some other words to comprehend the passages better. To avoid such problems, the researchers asked the participants not to use the dictionary in the main study. In addition, the time needed for the test administration was considered in the pilot test. Kuder-Richardson reliability coefficient (K-R 21) formula [31, 32] was applied to estimate the internal consistency. The reliability coefficients for the receptive and productive tests were 0.86 and 0.82 , respectively.

\subsubsection{Reading Comprehension Passages. Seven expository} passages were employed in this study. The thematically related passages were used for experimental group and passages of different topics were selected for control group. The researchers edited the selected passages in such a way that the passages would be in correspondence with the students' level. Each passage contained 10 target words. The researchers also modified the passages so that difficult words were used in a context in which the participants could easily understand.

The topics were chosen based on the familiarity of the topics to the participants. In fact, the topics were previously covered in the participants' textbook, and so the participants were familiar with those topics. No marginal glossary was provided in the additional three reading texts assigned to each group. Four passages were prepared on the topic of cellphones; one of them was the main passage considered for both groups (Appendix B). While experimental group studied three thematically related passages on cellphones, the control group read three passages on different topics such as smoking, global warming, and money. The passages were selected from English Daily website [33-35] and Select Readings [36]. The researchers verified the difficulty of the passages using Flesch Kincaid Grade Level. The researchers selected the passages of approximately 7.5 to 9.5 indicating that the passages were suitable for the senior high school students [37]. There were 411 to 462 words in each passage (Table 1). The target words occurred in all passages, but they were glossed in English only in the margin of the main passage. In each session, one passage was given to the participants.
2.2.4. Immediate and Delayed Posttests. The immediate posttest was administered at week 5, two days after the end of the treatment. Two different measures were used to assess receptive and productive vocabulary knowledge. The researchers prepared 15 questions for receptive vocabulary knowledge and 15 sentences for productive vocabulary. In other words, each test included 30 items, 15 receptive and 15 productive questions. The immediate posttest was used to examine whether learners learned new words from reading and can recall the acquired words. It was conducted immediately after the treatment and the first delayed posttest was administered two weeks later. The time of the second delayed posttest was considered two weeks after the first delayed ( 4 weeks after the end of the treatment). The delayed posttest was used to see whether vocabulary retention occurred through NR.

2.2.5. Receptive and Productive Vocabulary Tests. Receptive knowledge of the participants was analyzed via multiplechoice tests. Three types of receptive tests were administered for the study. One test was considered for immediate posttest and the other two receptive tests were administered as delayed posttests. In each posttest, there were 15 receptive vocabulary items. The tests included 10 items for the 10 target words and the remaining 5 items were considered as distractors. The test was scored dichotomously, with 1 point awarded to a correct answer and zero to an incorrect answer.

Similar to the receptive tests, the three productive tests were administered to measure the participants' productive vocabulary knowledge. Tests were equivalent versions of Laufer and Nation [20]. Each posttest included 15 items of productive vocabulary test in the form of word completion. The participants were asked to complete the words in context. Based on Laufer and Nation [20], the first letter or letters of target words were given to the students. In scoring, the answers that had minor spelling errors with one or two letter mistakes were awarded 0.5 points and the correct answer was awarded 1 point. Two raters scored the productive test at each posttest. The interrater reliability of the immediate, first delayed, and second delayed posttests was $0.92,0.95$, and 0.94 , respectively $(p<0.001)$. The mean scores of the two scorers at each posttest were considered as the participants' scores on the productive tests. The reliability coefficients for the receptive and productive vocabulary tests were also calculated through test-retest method. It was calculated by SPSS v.20. The Pearson correlation coefficients between receptive and productive posttests are shown in Table 2.

2.3. Procedures. In the first week of the study, the pretests were administrated to detect to ensure that prior knowledge 
TABLE 2: Pearson correlation coefficients between the posttests.

\begin{tabular}{|c|c|c|c|c|c|c|}
\hline & \multicolumn{3}{|c|}{ Receptive posttests } & \multicolumn{3}{|c|}{ Productive posttests } \\
\hline & 1 & 2 & 3 & 1 & 2 & 3 \\
\hline (1) Immediate posttest & - & & & - & & \\
\hline (2) First delayed posttest & $0.89^{*}$ & - & & $0.85^{*}$ & - & \\
\hline (3) Second delayed posttest & $0.83^{*}$ & $0.81^{*}$ & - & $0.87^{*}$ & $0.90^{*}$ & - \\
\hline
\end{tabular}

TABle 3: Procedures of the study.

\begin{tabular}{lcc}
\hline Week & Experimental group & Control group \\
\hline 1 & Reading the main passage (the mobile phones) & Pretest \\
2 & A passage on the same topic (dangers of cellphones) & Reading the main passage (the mobile phones) \\
3 & A passage on the same topic (mobile phone as a technology) & A passage on a different topic (global warming) \\
4 & A passage on the same topic (cellphones at school) & A passage on a different topic (money is a key to happiness) \\
5 & Immediate posttest & Delayed posttest 1 \\
7 & Delayed posttest 2 \\
9
\end{tabular}

of target words does not affect the results of the study. In addition, some experienced teachers proved that the participants' textbooks did not cover any of the words and the words were new to all students. Afterwards, the participants were randomly assigned to two groups, a control group and an experimental group including 30 students each. Seven reading comprehension passages were used for treatment. Each passage contained 10 target words. The participants in each group were asked to focus on the meaning and content of the passages. One week after the pretest, all participants received the main passage. All target words occurred in all passages and were glossed in English only in the margin of the main passage to draw the attention of the students to the words. Some other words, which were likely to hinder learners' comprehension, were glossed as well. The teacher checked the participants' understanding by asking them some questions. The participants individually completed some comprehension questions in true/false format. After reading the main passage, the experimental group continued to read articles addressing the issue of cellphone. The three passages were similar in terms of length, difficulty, and content. The control group read passages on different topics (i.e., global warming, money, and smoking). No marginal glossary provided in the additional three reading passages assigned to each group. On average, there were approximately 450 words in each passage. Right after the treatment, the students received an immediate posttest, both receptive and productive tests administered two days after the treatment. The tests were administered in an order which the information learned from one test would not be transferred to another, first productive questions and then receptive tests. Two weeks later, a delayed posttest was given to students. At the end of the ninth week from the beginning of the instruction, the participants took another delayed posttest. The previous studies lacked multiple delayed posttests to measure the participants' retention, but in this study, there were two delayed posttests. Table 3 illustrates the procedures of the study.

2.4. Data Analysis. The purpose of this study was to determine the effectiveness of NR on vocabulary recall and retention of EFL students. First, the groups' differences before the treatment were tested through independent samples $t$ tests. Afterwards, in order to answer the research questions, data from receptive and productive tests on immediate and two delayed posttests were analyzed and compared via two-way repeated measures ANOVA, Bonferroni pairwise comparisons, and independent samples $t$-tests.

\section{Results}

3.1. Results of Descriptive Statistics. Table 4 shows the mean (M), standard deviation (SD), and the number of participants $(n)$ in each group.

Table 4 displays that the experimental group obtained higher mean scores at three posttests. Table 5 shows the descriptive statistics of the productive vocabulary test over time.

Table 5 displays that the experimental group had higher mean score in immediate posttest, first delayed posttest, and second delayed posttest compared with those of the control group. In other words, the control group obtained lower mean scores at three posttests.

3.2. Results of Inferential Statistics. First, to investigate whether the performance of the two groups differed on the pretests, independent samples $t$-tests were conducted for both receptive and productive vocabulary pretests (Table 6).

As Table 6 shows, there were no statistically significant differences between the experimental and control groups 
TABLE 4: Descriptive statistics for the receptive vocabulary tests.

\begin{tabular}{lccccccccc}
\hline \multirow{2}{*}{ Group } & \multirow{2}{*}{$n$} & \multicolumn{2}{c}{ Pretest } & \multicolumn{2}{c}{ Immediate posttest } & \multicolumn{2}{c}{ 1st delayed posttest } & \multicolumn{2}{c}{ 2nd delayed posttest } \\
& & M & SD & M & SD & M & SD & M & SD \\
\hline Experimental & 30 & 0.80 & 0.847 & 7.43 & 1.01 & 5.80 & 0.99 & 4.76 & 1.00 \\
Control & 30 & 0.73 & 0.828 & 6.26 & 1.02 & 4.66 & 0.76 & 2.87 & 0.94 \\
\hline
\end{tabular}

TABLE 5: Descriptive statistics for the productive vocabulary tests.

\begin{tabular}{lcccccccc}
\hline \multirow{2}{*}{ Group } & \multirow{2}{*}{$n$} & \multicolumn{2}{c}{ Pretest } & \multicolumn{2}{c}{ Immediate posttest } & \multicolumn{2}{c}{ 1st delayed posttest } & \multicolumn{2}{c}{ 2nd delayed posttest } \\
& & $\mathrm{M}$ & $\mathrm{SD}$ & $\mathrm{M}$ & $\mathrm{SD}$ & $\mathrm{M}$ & $\mathrm{SD}$ & $\mathrm{M}$ \\
\hline Experimental & 30 & 0.10 & 0.305 & 6.40 & 0.98 & 5.87 & 1.02 & 4.37 \\
Control & 30 & 0.07 & 0.254 & 5.32 & 1.03 & 3.93 & 0.96 & 2.86 \\
\hline
\end{tabular}

TABLE 6: Independent samples $t$-tests for the receptive and productive pretests.

\begin{tabular}{|c|c|c|c|c|c|}
\hline Pretest & Mean difference (experimental-control) & Std. error difference & $t$ & df & $p$ \\
\hline Receptive test & 0.07 & 0.22 & 0.31 & 58 & 0.76 \\
\hline Productive test & 0.03 & 0.07 & 0.46 & 58 & 0.65 \\
\hline
\end{tabular}

TABle 7: Two-way repeated measures ANOVA analysis for the receptive posttests.

\begin{tabular}{lccc}
\hline Source & df & $F$ & $p$ \\
\hline Between subjects & & & \\
$\quad$ Group & 1 & 3564.74 & 0.00 \\
Within subjects & & & \\
$\quad$ Time & 2 & 241.22 & 0.00 \\
$\quad$ Time $\times$ group & 2 & 4.62 & 0.00 \\
\hline
\end{tabular}

TABLE 8: Two-way repeated measures ANOVA analysis for the productive posttests.

\begin{tabular}{lccc}
\hline Source & df & $F$ & $p$ \\
\hline Between subjects & & & \\
$\quad$ Group & 1 & 1811.92 & 0.00 \\
Within subjects & & & \\
$\quad$ Time & 2 & 114.03 & 0.00 \\
$\quad$ Time $\times$ group & 2 & 3.96 & 0.00 \\
\hline
\end{tabular}

in the pretests. To compare the experimental and control groups' scores on all three posttests, a series of two-way repeated measures ANOVA were run in which the vocabulary test scores were entered as the dependent variable and time (immediate and two delayed posttests) and the treatment as independent variables. Table 7 shows the results of two-way repeated measures ANOVA for the receptive posttests.

As Table 7 depicts, there was a significant interaction between time and group, and there was a significant difference considering the time. Moreover, the significant differences were found between the participants in all three receptive posttests. Table 8 shows the results of two-way repeated measures ANOVA for the productive posttests.

Table 8 shows that there was a significant interaction between time and group and there was a significant difference

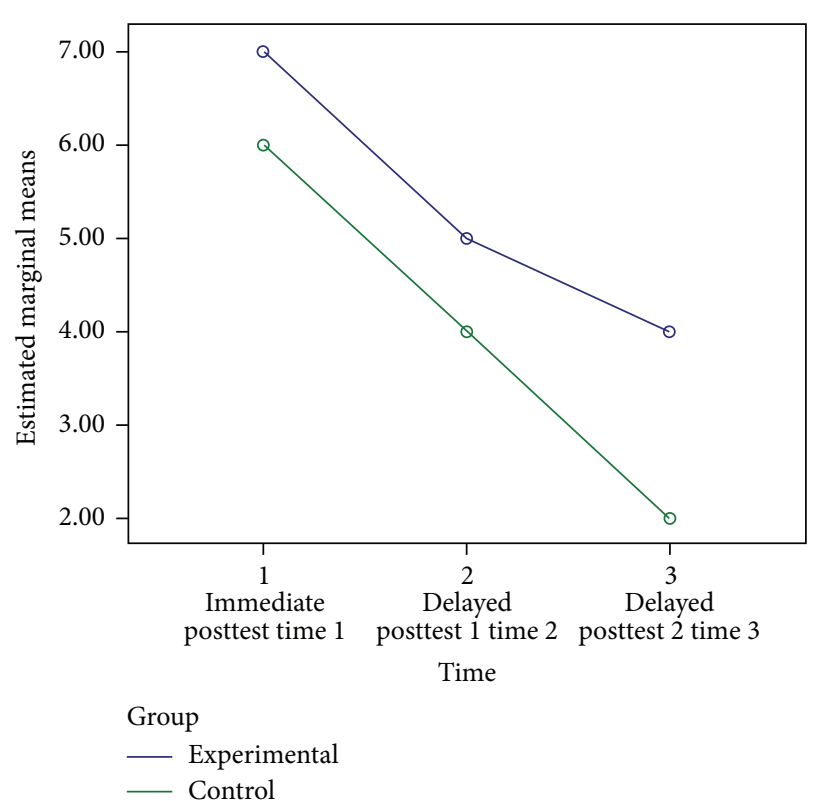

FIGURE 1: Mean changes of the participants' scores on receptive vocabulary posttests.

found in terms of time. Furthermore, a significant difference was found between the participants in all three posttests. Figure 1 displays the mean changes of receptive vocabulary test scores for the experimental and control groups over three posttests.

As Figure 1 shows, the experimental group performed better than the control group on immediate and two delayed receptive posttests. Figure 2 depicts the mean changes for two groups in productive test over the three posttests. Figure 2 illustrates that the participants in the experimental group outperformed the control group at all productive vocabulary posttests. 


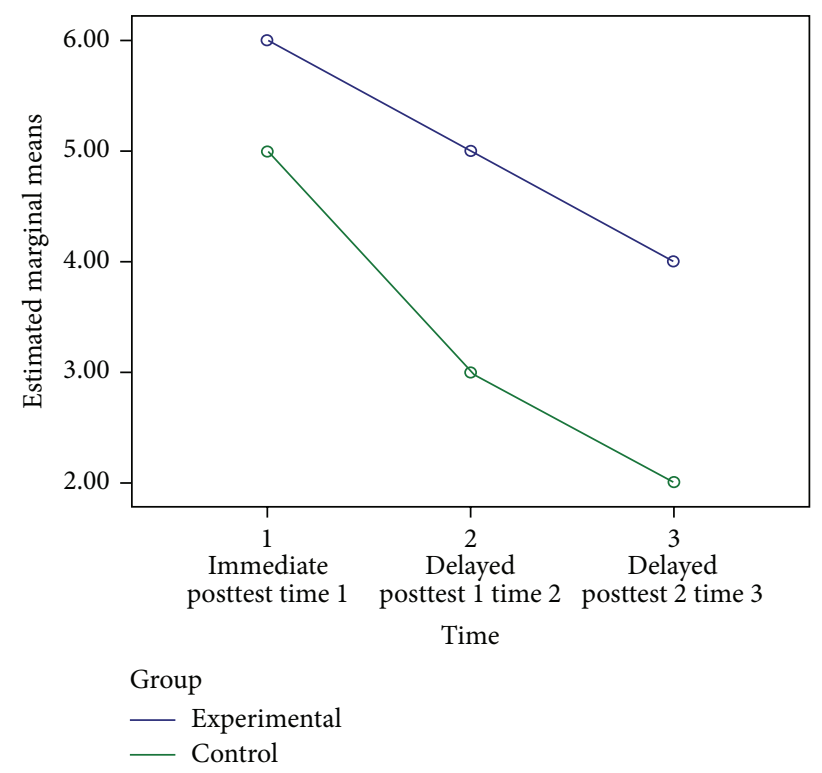

FIGURE 2: Mean changes of the participants' scores on productive vocabulary posttests.

TABle 9: Bonferroni pairwise comparisons for the receptive posttests.

\begin{tabular}{lccc}
\hline Time $(I)$ & Time $(J)$ & Gain & $p$ \\
\hline Time 1 & Time 2 & 1.62 & 0.00 \\
Time 2 & Time 3 & 1.42 & 0.00 \\
Time 1 & Time 3 & 3.03 & 0.00 \\
\hline
\end{tabular}

TABLE 10: Bonferroni pairwise comparisons for the productive posttests.

\begin{tabular}{lccc}
\hline Time $(I)$ & Time $(J)$ & Gain & $p$ \\
\hline Time 1 & Time 2 & 0.96 & 0.00 \\
Time 2 & Time 3 & 1.28 & 0.00 \\
Time 1 & Time 3 & 2.42 & 0.00 \\
\hline
\end{tabular}

Table 9 presents the Bonferroni pairwise comparisons for the experimental group in all receptive posttests. It shows the gain scores of the experimental group at the posttests. Time 1 is immediate posttest that is compared with the first delayed posttest (time 2) and second delayed posttest (time 3).

Bonferroni post-hoc comparisons showed significant differences between the receptive posttests for the experimental group (Table 8). Table 9 displays the Bonferroni post-hoc comparisons in productive posttests. Table 10 shows significant difference between the productive posttests.

To investigate whether the performance of the two groups differed on any of the posttests, independent samples $t$ tests were also conducted for both receptive and productive vocabulary posttests (Tables 11 and 12).

As Table 11 displays, all these tests were significant indicating that the experimental group consistently outperformed the control group. The results suggest that NR led to better gains in the participants' receptive vocabulary knowledge than reading of unrelated topics.
Table 12 illustrates the results of independent sample $t$ test for the productive vocabulary posttests. The gains were statistically significant, and they indicate that the experimental group consistently outperformed the control group in the productive posttests.

\section{Discussion}

The purpose of this study was to determine the effect of NR on EFL learners' vocabulary recall and retention. According to the results of this study, the answer to the first research question was positive since the experimental group outperformed the control group in all three receptive posttests. In other words, the participants provided with NRs had significantly more ability in receptive vocabulary recall than participants in the control group. One possible explanation of such a result is that growth in learners' receptive vocabulary recall can be related to the repeated encounters with the thematic concept which helped learners develop semantic networks around the words. Tinkham [38] found that presenting new L2 words in thematically related sets facilitates the learning of those words, as compared to presenting new words in unrelated sets. Thus, the NR condition might have improved learners' ability to thematically integrate the content-related target words, thereby contributing to accessibility to the words easily.

The findings of this study are consistent with the results of the study by Kang [28] that NR considerably facilitated learners' understanding of meanings of target words and the ability to appropriately use them in context. However, Kang's [28] study did not have any delayed posttests to focus on vocabulary retention, but the present study benefited from two delayed posttests to examine the learners' vocabulary retention. The participants in the experimental group were more successful in recalling the target words than the control group. The control group who read thematically unrelated passages exhibited lower scores than the experimental group in both productive and receptive vocabulary tests because the lack of relatedness in topics made it less likely for learners to learn the vocabulary of the passages. The results of this study support Krashen's input hypothesis [21] that language is acquired when learners are exposed to a large amount of comprehensible input, at or just beyond their present level of language knowledge and skills. Comprehensible input is easy to provide through NR because common vocabulary is repeated within thematically related texts or similar contexts. In NR, content is utilized to promote language learning, with the primary aim of acquiring language skills in meaningful contexts. Moreover, the findings are in line with Cho et al.s [6] study that found positive effects of NR on vocabulary acquisition.

The results of the study also revealed the positive effect of NR on participants' receptive vocabulary retention. The researchers examined the participants' vocabulary retention by means of two delayed posttests and according to the findings, the experimental group had higher scores in receptive vocabulary retention than control group. The participants' retention of target words in the two delayed posttests was affected positively by NR. Learners who received treatment 
TABLE 11: Independent samples $t$-tests for the receptive posttests.

\begin{tabular}{|c|c|c|c|c|c|}
\hline Posttest & Mean difference (experimental-control) & Std. error difference & $t$ & df & $p$ \\
\hline Immediate & 1.167 & 0.261 & 4.471 & 58 & 0.00 \\
\hline First delayed & 1.133 & 0.229 & 4.958 & 58 & 0.00 \\
\hline Second delayed & 1.900 & 0.251 & 7.568 & 58 & 0.00 \\
\hline
\end{tabular}

TABLE 12: Independent samples $t$-tests for the productive posttests.

\begin{tabular}{|c|c|c|c|c|c|}
\hline Posttest & Mean difference (experimental-control) & Std. error difference & $t$ & df & $p$ \\
\hline Immediate & 1.083 & 0.259 & 4.180 & 58 & 0.00 \\
\hline First delayed & 1.933 & 0.256 & 7.564 & 58 & 0.00 \\
\hline Second delayed & 1.500 & 0.299 & 5.012 & 58 & 0.00 \\
\hline
\end{tabular}

outperformed those who received no treatment in two delayed posttests even though both groups showed decrease in their mean scores over time. This means that the provision of NR for experimental group had a significant effect, enabling the learners to see target words in thematically related texts. The reason behind this result is that repeated exposures to target words through NR improved the productive dimension of vocabulary knowledge. In order to use a word competently, learners must know more than basic meaning of a word, and abundant exposures to words through narrow input could create the conditions for outgrowth of knowledge about a word's usage, including a word's grammatical behavior and part of speech.

Similar to the results of the two receptive tests, the NR group significantly outperformed the control group on the productive tests. This indicates that even though NR does not entail the use of productive vocabulary knowledge, it can contribute to development of productive vocabulary knowledge. The findings also support Schmitt and Carter [39] who believed that NR can facilitate the productive dimension of vocabulary knowledge. They found that topically related newspaper stories repeated content words more often than unrelated stories.

The results also showed the language attrition phenomenon on the retention tests. Both groups regressed significantly one month after the related instructions ended. The control group regressed more than their NR counterparts in the receptive test (Table 11) implying that NR group could better recognize the target words in context. However, the experimental group regressed more than their control counterparts in the productive test (Table 12) indicating that although NR could better produce the target words in context, the attrition of productive knowledge was more than that of the control group. It can be concluded that in long-term retention of words, NR can be more effective if it can be accompanied with other vocabulary enhancement techniques (e.g., boldfacing, italicizing, underlining, or highlighting) [27].

\section{Conclusion}

The major finding of this study was that NR and multiple exposure of target words in topic-related passages improved
EFL students' vocabulary recall and retention. NR provided greater opportunities for repetition of words in passages of the same topic and in turn consolidation of knowledge of unknown and partially known words. In sum, the NR can be an effective approach for vocabulary development and spatially for learners' vocabulary recall and retention. Reading some thematically related texts has a great impact on incidental vocabulary learning of EFL/ESL learners. The overall conclusion would be that NR can greatly contribute to incidental vocabulary learning [40].

The findings of this study are primarily beneficial to EFL learners who specifically intend to make improvements in their vocabulary knowledge. This approach of reading helps them become aware of the significance of learning new words in context rather than in isolation. Because the majority of L2 learners struggle to learn vocabulary, greater emphasis on NR in the classrooms and developing motivated readers may provide the best path for vocabulary recall and retention. Secondly, the findings of this research can be helpful for language teachers as they gain insight into an approach of reading to vocabulary development. Curriculum designers and material developers should be aware of the positive role of NR and its benefits for students' vocabulary recall and retention. Another implication is related to how the materials for NR can be prepared. The Internet is an invaluable source for locating and collecting such material. In this study, some NR texts were generated by drawing from online texts of a particular issue. Using such an accessible and resourceful tool can help L2 teachers easily incorporate NR into their classrooms. Moreover, in a content-based approach, classroom activities are specific to the subject matter being taught. In this respect, NR lends itself quite naturally to CBI.

No study is devoid of limitations, and the present study is no exception. In this study, the participants' reading comprehension was not measured on the posttests. Thus, in future research on vocabulary learning through NR, information on the level of comprehension of narrow text and vocabulary learning would better help researchers understand the mechanism behind vocabulary learning through narrow texts. In addition, this study was conducted on lower-intermediate level EFL learners. Further studies can be conducted on other levels of English proficiency. Furthermore, in future studies, various types of vocabulary tests can be applied to measure 
TABLE 13

\begin{tabular}{lc}
\hline Word & Parts of speech \\
\hline Alleviate & Verb \\
Anticipate & Verb \\
Ban & Noun \\
Convenient & Adjective \\
Debate & Noun \\
Detect & Verb \\
Expert & Noun \\
Hazard & Noun \\
Impact & Verb \\
Merit & Noun \\
\hline
\end{tabular}

EFL/ESL learners' vocabulary knowledge. In this study, the majority of the participants came from middle-class families. Future studies can consider the mediating effects of social class, parents' education, and family income on vocabulary learning through NR.

\section{Appendix}

\section{A. List of Target Words}

See Table 13.

\section{B. Main Passage for Both Groups}

Mobile Phones: Hang Up or Keep Talking. Millions of people are using cellphones today. In many places, it is actually considered unusual not to use one. In many countries, cellphones are very popular with young people. They find that the phones are more than a means of communication and they know that cellphones have many merits for them: having a mobile phone shows that they are connected to everyone and everyplace.

The big change around the world in mobile phone use has made some health professionals worried. Some doctors are concerned that in the future many people may suffer health problems and hazards from the use of mobile phones. In England, there has been a serious debate about this issue. Mobile phone companies are worried about the negative effect of such ideas on people. They say there are no proofs that mobile phones have bad impact on your health. On the other hand, some medical studies show changes in the brain cells of some people who use mobile phones. So they believe in some kind of ban in using mobile phones.

Signs of change in the tissues of the brain and head can be discovered with modern scanning equipment. In one case, a traveling salesman had to retire at a young age because of serious memory loss. He could not remember even simple tasks. He would often forget the name of his own son. This man used to talk on his mobile phone for about six hours a day, every day of his working week, for a couple of years. His family doctor blamed his mobile phone use but his employer's doctor did not agree.
What is it that makes mobile phones potentially harmful? The answer is radiation. High-tech machines can detect very small amounts of radiation from mobile phones. Mobile phone companies and some experts agree that there is some radiation, but they say the amount is too small to worry about. As the discussion about their safety continues, it appears that it is best to use mobile phones less often. Use your regular phone if you want to talk for a long time. Use your mobile phone only when you really need it. Mobile phones also have some benefits. It can be very useful and convenient, especially in emergencies. On the other hand, it is anticipated that cellphones threat human's health. It means in the future mobile phones may have a warning label that says they are bad for your health. Therefore, to alleviate the dangers and problems for now, it is wise not to use your mobile phone too often.

\section{Competing Interests}

The authors declare that they have no competing interests.

\section{References}

[1] I. S. P. Nation, Learning Vocabulary in Another Language, Cambridge University Press, Cambridge, UK, 2001.

[2] S. Gass, "Integrating research areas: a framework for second language studies," Applied Linguistics, vol. 9, no. 2, pp. 233-252, 1999.

[3] E. J. Ponniah, "Incidental acquisition of vocabulary by reading," The Reading Matrix, vol. 11, no. 2, pp. 135-139, 2011.

[4] W. Kintsch, Comprehension: A Paradigm for Cognition, Cambridge University Press, Cambridge, UK, 1998.

[5] S. Krashen, "We acquire vocabulary and spelling by reading: additional evidence for the input hypothesis," The Modern Language Journal, vol. 73, no. 4, pp. 440-464, 1989.

[6] K. Cho, K. Ahn, and S. Krashen, "The effects of narrow reading of authentic texts on interest and reading ability in English as a foreign language," Reading Improvement, vol. 42, no. 1, pp. 5864, 2005.

[7] S. Krashen, “The case for narrow reading," Language Magazine, vol. 3, no. 5, pp. 17-19, 2004.

[8] K. Poolsawad, S. Kanjanawasee, and J. Wudthayagorn, "Development of an English communicative competence diagnostic approach," Procedia-Social and Behavioral Sciences, vol. 191, pp. 759-763, 2015.

[9] D. Hymes, "On communicative competence," in Sociolinguistics, J. B. Pride and J. Holmes, Eds., pp. 269-293, Penguin Education, Penguin Books, Baltimore, Md, USA, 1972.

[10] M. Canale and M. Swain, "Theoretical bases of communicative approaches to second language teaching and testing," Applied Linguistics, vol. 1, no. 1, pp. 1-47, 1980.

[11] "Rethinking the role of communicative competence," in Intercultural Language Use and Language Learning, M. CelceMurcia, E. Alcon, and M. P. Safont, Eds., pp. 41-57, Springer, Dordrecht, Netherlands, 2007.

[12] N. Schmitt, Vocabulary in Language Teaching, Cambridge University Press, Cambridge, UK, 2000.

[13] I. S. P. Nation, "Research into practice: vocabulary," Language Teaching, vol. 44, no. 4, pp. 529-539, 2011. 
[14] W. M. Rivers, Communicating Naturally in a Second Language, Cambridge University Press, Cambridge, UK, 1983.

[15] M. T. Farvardin, The effect of different types of glosses on incidental vocabulary learning and reading comprehension across text types [M.A. thesis], University of Kashan, Kashan, Iran, 2009, http://ganj.irandoc.ac.ir/articles/download_sparse/496391.

[16] B. Laufer, "Vocabulary acquisition in a second language: do learners really acquire most vocabulary by reading? Some empirical evidence," Canadian Modern Language Review, vol. 59, no. 4, pp. 567-587, 2003.

[17] J. H. Hulstijn, "Intentional and incidental second language vocabulary learning: a reappraisal of elaboration, rehearsal and automaticity," in Cognition and Second Language Instruction, P. Robinson, Ed., pp. 258-286, Cambridge University Press, Cambridge, UK, 2001.

[18] T. Huckin and J. Coady, "Incidental vocabulary acquisition in a second language," Studies in Second Language Acquisition, vol. 21, no. 2, pp. 181-193, 1999.

[19] E. Hatch and C. Brown, Vocabulary, Semantics, and Language Education, Cambridge University Press, Cambridge, UK, 1995.

[20] B. Laufer and P. Nation, "A vocabulary-size test of controlled productive ability," Language Testing, vol. 16, no. 1, pp. 33-51, 1999.

[21] S. Krashen, The Input Hypothesis: Issues and Implications, Addison-Wesley Longman Ltd, New York, NY, USA, 1985.

[22] M. Horst, "Learning L2 vocabulary through extensive reading: a measurement study," Canadian Modern Language Review, vol. 61, no. 3, pp. 355-382, 2005.

[23] T. S. Paribakht and M. Wesche, "Reading and incidental L2 vocabulary acquisition- an introspective study of lexical inferencing," Studies in Second Language Acquisition, vol. 21, no. 2, pp. 195-224, 1999.

[24] K. Cho and S. Krashen, "Acquisition of vocabulary from the Sweet Valley Kids series," Journal of Reading, vol. 37, no. 8, pp. 662-667, 1994.

[25] M. Pigada and N. Schmitt, "Vocabulary acquisition from extensive reading: a case study," Reading in a Foreign Language, vol. 18, no. 1, pp. 1-28, 2006.

[26] R. Waring and M. Takaki, "At what rate do learners learn and retain new vocabulary from reading a graded reader," Reading in a Foreign Language, vol. 15, no. 2, pp. 1-27, 2003.

[27] H.-T. Min, "EFL vocabulary acquisition and retention: reading plus vocabulary enhancement activities and narrow reading," Language Learning, vol. 58, no. 1, pp. 73-115, 2008.

[28] E. Y. Kang, "Promoting L2 vocabulary learning through narrow reading," RELC Journal, vol. 46, no. 2, pp. 165-179, 2015.

[29] D. Allan, Oxford Placement Test, Oxford University Press, Oxford, UK, 2004.

[30] M. Bromberg, J. Lieb, and A. Traiger, 504 Absolutely Essential Words, Barron's Educational Series, Hauppauge, NY, USA, 2011.

[31] E. Hatch and A. Lazaraton, The Research Manual, Newbury House, New York, NY, USA, 1991.

[32] J. C. Richards and R. W. Schmidt, Longman Dictionary of Language Teaching and Applied Linguistics, Routledge, 2013.

[33] English Daily Organization, "Global warming," 2016, http:// www.englishdaily626.com/lower_secondary_english_essays .php?422.

[34] English Daily Organization, "Money is the key to happiness," 2016, http://www.englishdaily626.com/high_school_english_ essays.php?507.
[35] English Daily Organization, Why smoking is bad for everyone, 2016, http://www.englishdaily626.com/summary.php?077.

[36] L. Lee and E. Gundersen, Select Reading: Pre-Intermediate, Oxford University Press, London, UK, 2011.

[37] M. Zamanian and P. Heydari, "Readability of texts: state of the art," Theory and Practice in Language Studies, vol. 2, no. 1, pp. 43-53, 2012.

[38] T. Tinkham, "The effects of semantic and thematic clustering on the learning of second language vocabulary," Second Language Research, vol. 13, no. 2, pp. 138-163, 1997.

[39] N. Schmitt and R. Carter, "The lexical advantages of narrow reading for second language learners," TESOL Journal, vol. 9, no. 1, pp. 4-9, 2000.

[40] N. Daskalovska, "Incidental vocabulary acquisition from reading an authentic text," The Reading Matrix, vol. 14, no. 2, pp. 12 $27,2014$. 


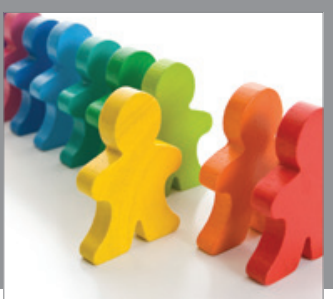

Autism

Research and Treatment
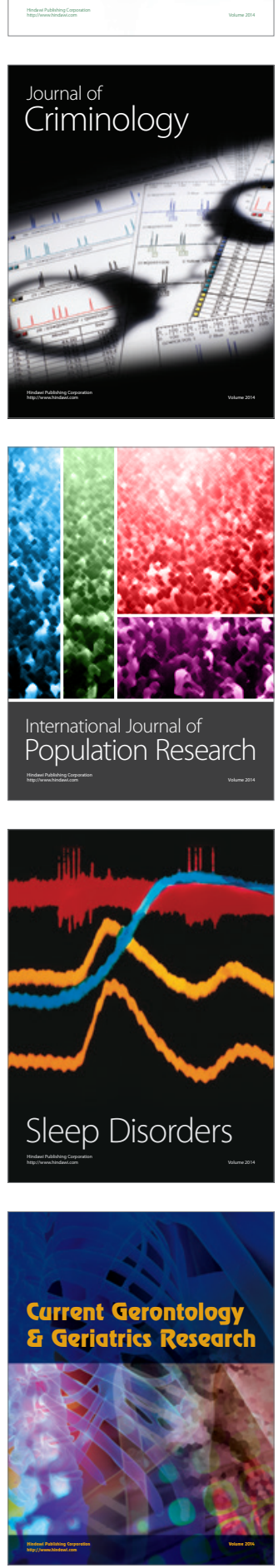

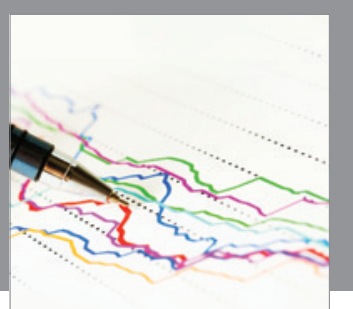

Economics

Research International
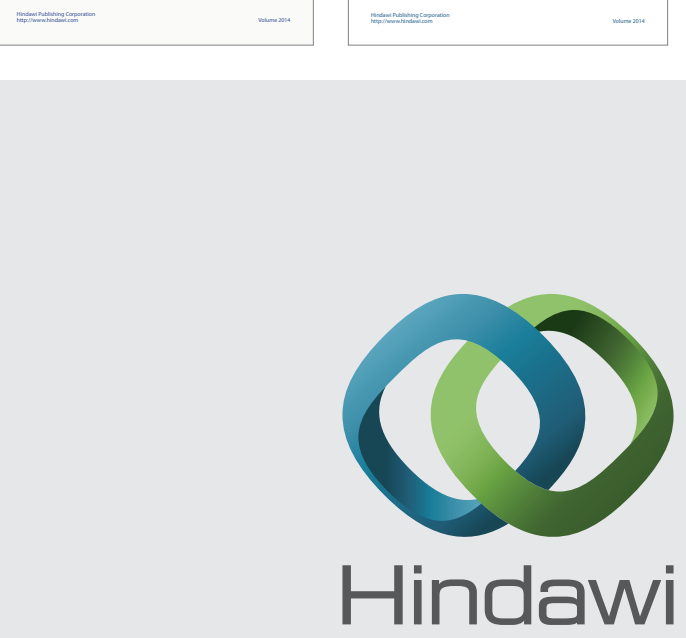

Submit your manuscripts at

http://www.hindawi.com
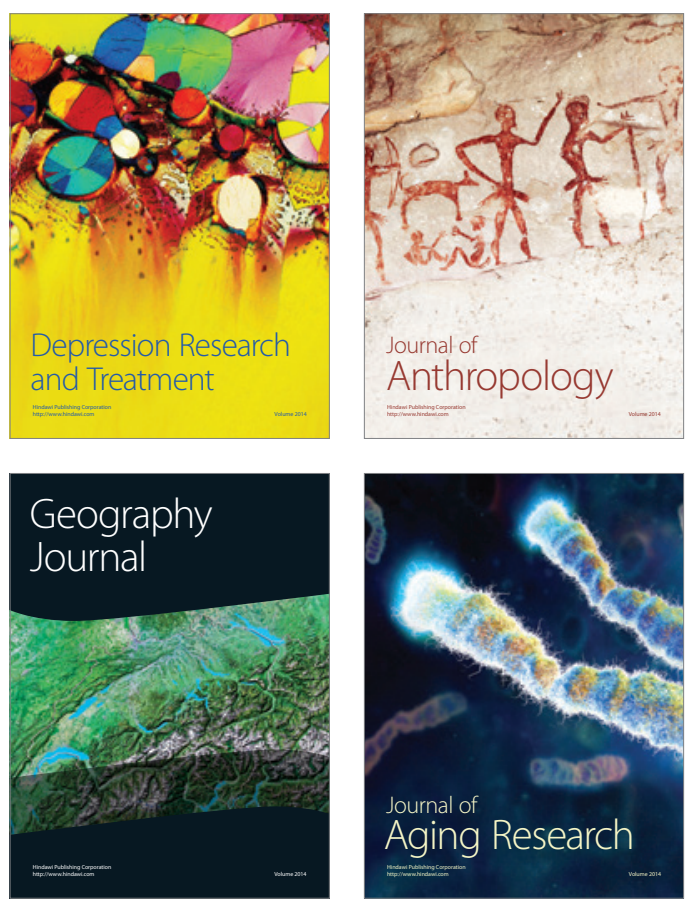
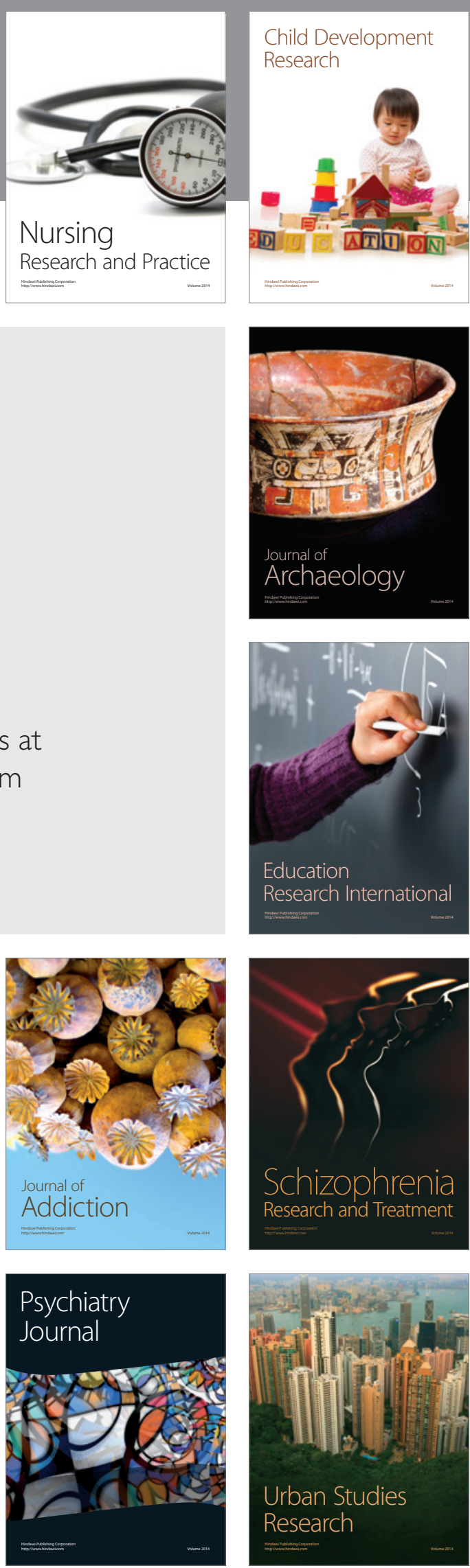